\title{
Integration of Triboluminescent EuD 4 TEA Crystals to Transparent Polymers: Impact Sensor Application
}

\author{
Anıl İncel, ${ }^{\dagger}$ Mehtap Emirdag-Eanes, ${ }^{\dagger}$ Colin D. McMillen, ${ }^{\S}{ }^{\circledR}$ and Mustafa M. Demir*, ${ }^{\dagger}$ \\ ${ }^{\dagger}$ Department of Materials Science and Engineering and Department of Chemistry, İzmir Institute of Technology, Urla, 35430 İzmir, \\ Turkey \\ ${ }^{\S}$ Department of Chemistry, Clemson University, 219 Hunter Laboratories, Clemson, South Carolina 29634, United States
}

Supporting Information

ABSTRACT: Lanthanide-based organometallic materials are well-known candidate triboluminescent (TL) materials that can show bright emission when a mechanical force is applied. These materials are usually in the form of crystalline powders, and it is often useful to integrate these samples into a polymer matrix in order to achieve processability, enabling coating from a solution/molten state or fabrication as a complex-shaped matrix. In this work, micrometer-sized europium tetrakis (dibenzoylmethide) triethylammonium $\left(\mathrm{EuD}_{4} \mathrm{TEA}\right)$ crystals were synthesized and integrated with various transparent polymers (PMMA, PS, PVDF, and PU) using two approaches: (i) blending and (ii) surface impregnation. In the former method, the crystalline particles were molecularly dissolved; therefore, a TL response cannot be achieved. More than $10 \mathrm{wt} \% \mathrm{TL}$ crystals in the composite is needed to obtain TL signals. However, TL signal was achieved at 2.5 wt \% when a composite was prepared by the latter approach. TL intensity shows exponential decay with consecutive mechanical action. The TL emission of PU-based surface impregnated composite expires with long-lived emission, and maximum TL response with respect to applied force was measured between 2.45 and $42.0 \mathrm{~N}$.

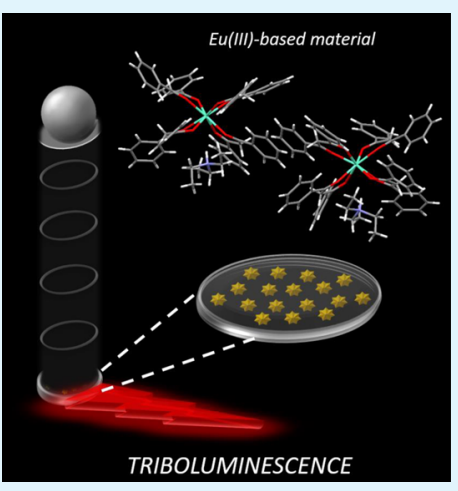

KEYWORDS: blending, optical composites, piezoelectricity, single-crystal X-ray diffraction, surface impregnation, triboluminescence

\section{INTRODUCTION}

Damage sensing in situ has been extensively used for the early state detection of bulk systems, which hints about the sudden fracture of structural components or catastrophic failure. ${ }^{1,2}$ The fabrication of an impact sensor by using triboluminescent (TL) materials promises to be a highly effective sensing platform, which provides simple, easy, real-time continuous monitoring of both the magnitude and the location of damage. ${ }^{3-5} \mathrm{TL}$ is defined as the light emission resulting from the breaking of chemical bonds in the crystalline structure upon application of mechanical force. The development of TL crystals that are selfresponsive to the application of mechanical force is an emerging field of research that merges the advantages of TL materials with those of damage sensing technology. ${ }^{6-11} \mathrm{~A}$ number of TL materials have been reported in literature such as $\mathrm{ZnS} ;{ }^{12} \mathrm{Y}_{2} \mathrm{O}_{3}$ and $\mathrm{Y}_{2} \mathrm{O}_{3}: \mathrm{Eu}^{13}(\mathrm{Ca}, \mathrm{Mg}) \mathrm{Al}_{2} \mathrm{O}_{4} ;{ }^{14} \mathrm{SrAl}_{2} \mathrm{O}_{4} ;{ }^{15} \mathrm{Ln}: \mathrm{SrAl}_{2} \mathrm{O}_{4}{ }^{16}$ $\mathrm{BaAl}_{2} \mathrm{SiO}_{8} ;{ }^{17} \mathrm{MgD}_{4} \mathrm{TEA} ;{ }^{18} \mathrm{Cu}(\mathrm{NCS})(\mathrm{py})_{2}\left(\mathrm{PPh}_{3}\right) ;{ }^{19} \mathrm{ZnO}$ tetrapods filled elastomers; ${ }^{11} \mathrm{ZnO}: \mathrm{Ln}^{20}{ }^{20}$ hexafluoroacetylacetonate (hfa) derivatives of Ln-based compounds; ${ }^{21}$ 3,6dibromocarbazole; ${ }^{22} \mathrm{~N}$-isopropylcarbazole; ${ }^{23}$ ester derivatives of 9-anthracenecarboxylic acid; ${ }^{24} \mathrm{~N}$-phenyl imide compounds; ${ }^{25} \mathrm{ZnO}$ nanotetrapods embedded PDMS ${ }^{26}$ tetrapod nanocrystals based electrospun composite; ${ }^{27}$ and tetrapodal ZnO-PDMS composites. ${ }^{28}$ The highest emission is achieved from europium tetrakis(dibenzoyl methide) triethylammonium, $\mathrm{EuD}_{4} \mathrm{TEA}$, that shows two times higher TL intensity than that of $\mathrm{ZnS}: \mathrm{Mn}$, which is known as the highest triboluminescent- emitting inorganic material. ${ }^{29} \mathrm{EuD}_{4} \mathrm{TEA}$, an organo-metallic based TL crystal, exhibits a highly fluorescent red emission. This molecule consists of one four-coordinated electrondonating group, 1,3-diphenyl-1,3-propanedione, as the lightharvesting and energy-transferring component, and one electron-withdrawing group, triethylamine, as an ancillary ligand to stabilize the crystal complex. ${ }^{30}$ This kind of tetrabidentate complex shows an eight-coordinate rare-earth propanedionate structural form with square-antiprism geometry. ${ }^{31}$ It has gained much interest due to clearly visible emission even in daylight under low pressure, high intensity response, and near-band-edge exciton emission at $614 \mathrm{~nm}$ where the triboluminescence emission occurs from ${ }^{5} \mathrm{D}_{0}$ to ${ }^{7} \mathrm{~F}_{2}$ transition line. ${ }^{29}$ Furthermore, extensive studies have been performed on $\mathrm{EuD}_{4} \mathrm{TEA}$ such as the effect of different solvents on the size and TL emission of crystalline particles, ${ }^{32}$ the advantages over other lanthanide-based $\mathrm{LnD}_{4}$ TEA complexes, ${ }^{33}$ the comparison of TL emission with inorganic, organic, and other organometallic TL compounds, ${ }^{34}$ and the dopant effects on TL emission. ${ }^{30,35,36}$ However, the application of $\mathrm{EuD}_{4} \mathrm{TEA}$, or any TL material, is currently limited to a sensing platform for monitoring damage due to the powder nature of the samples. The incorporation of luminescent crystals into solid polymer matrices is a critically

Received: December 20, 2016

Accepted: January 26, 2017

Published: January 26, 2017 
Scheme 1. Type of Process for the Preparation of TL/Polymer Composite: (a) Blending and (b) Surface Impregnation a) Blending

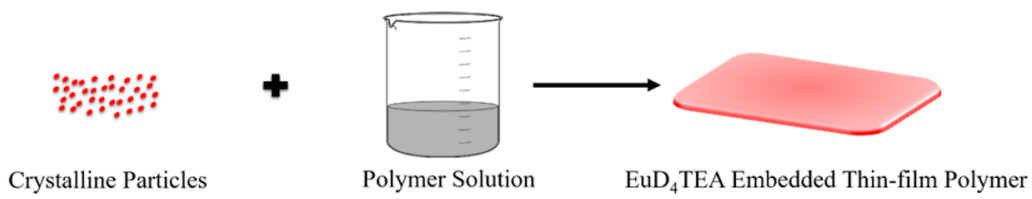

b) Surface Impregnation

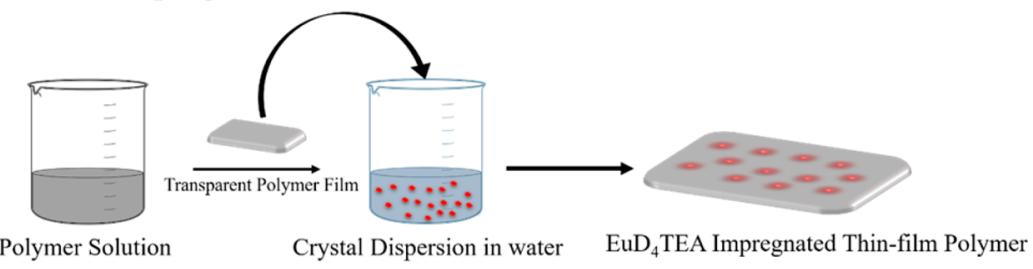

important advance that can broaden the applications of both TL materials and polymers by exploiting the multifunctionality of TL crystals. ${ }^{37-39}$

Previously, there has been an unprecedented surge of interest in such composites toward impact sensing and damage monitoring. Triboluminescence measurements and characterization of $\mathrm{ZnS}: \mathrm{Mn}$ were investigated by encapsulating polydimethylsiloxane, ${ }^{40}$ by dispersing it in unsaturated polyester resin, ${ }^{12}$ and by doping with unreinforced vinyl ester resin ${ }^{41}$ to understand the behavior of TL materials in polymer systems. Not only can polymer composites be prepared by using inorganic based $\mathrm{ZnS}: \mathrm{Mn}$ TL material, but the organometallic-based $\mathrm{EuD}_{4}$ TEA can also be used as a doping agent in polymers to likewise form composites. EuD $\mathrm{D}_{4}$ TEA added to poly(methyl methacrylate) (PMMA) as well as low-viscosity (Cytoseal 60) and high-viscosity (Cytoseal 280) toluene-based acrylic resins composites were obtained, and photoluminescence and TL response of composite were determined. ${ }^{42} \mathrm{TL}$ performance of PMMA-based composites showed better results than other matrices, and the increasing volume of PMMA into TL materials exhibited no TL emission at low impact. The blending of both $\mathrm{ZnS}: \mathrm{Mn}$ and $\mathrm{EuD}_{4} \mathrm{TEA}$ materials into different diblock copolymers by using a nitroxide-mediated polymerization was studied to clarify the surface selectivity of TL materials into a polymer matrix. ${ }^{43} \mathrm{ZnS}: \mathrm{Mn}$ and $\mathrm{EuD}_{4}$ TEA showed different surface activity toward amine and alcohol groups and stabilized the connectivity between polymer ligand and surface, respectively. The study on polyacrylamide-based hydrogels entrapment of TL crystals (Eu $\mathrm{Eu}_{4}$ TEA and $\mathrm{Cu}(\mathrm{NCS})$ $\left.(\mathrm{py})_{2}\left(\mathrm{PPh}_{3}\right)\right)$ resulted in improved $\mathrm{TL}$ intensity from the crystalline particles. ${ }^{44}$

In this study, $\mathrm{EuD}_{4}$ TEA crystalline particles were prepared and integrated with transparent polymers: poly(methyl methacrylate) (PMMA), polystyrene (PS), polyurethane (PU), and polyvinylidene fluoride (PVDF). The triboluminescent and piezoelectric properties of the resulting composite materials were studied with respect to variety of parameters such as polymer type and differences in experimental processing. Thus, the potential of $\mathrm{EuD}_{4} \mathrm{TEA}$ to be used as a damage sensor was proved by integration into transparent polymers to capture and transfer efficient optical signal produced by TL emission from transparent composite films. In order to fabricate $\mathrm{EuD}_{4} \mathrm{TEA} /$ polymer films, two methods were employed: (i) blending and (ii) surface impregnation. It was reported that the composites developed by surface impregnation method present highly desirable properties for damage sensors such as better optical stability, long-lived TL performance, and higher TL emission as a function of number of applied force; therefore, the damage sensing platform was generated as capacity for in situ sensing to detect the magnitude and the location of damage in real-time monitoring in the host polymeric material.

\section{EXPERIMENTAL DESIGN}

Materials and Methods. Europium(III) nitrate pentahydrate (99.9\% trace metal basis), 1,3,-diphenyl-1,3-propanedione (99.8\%), triethylamine $(\geq 99 \%)$, PMMA $(\sim 350 \mathrm{kDa})$, PS $(\sim 350 \mathrm{kDa})$, PU, PVDF ( 280 kDa), ethanol $(\geq 99.8 \%)$ were purchased from SigmaAldrich (St. Louis, MO, USA). All other reagents and solvents are available at analytical grade and were used as purchased. The single crystal X-ray diffraction data was collected at $100(2) \mathrm{K}$ on a Bruker D8 Venture Photon 100 using graphite-monochromated Mo K $\alpha$ radiation $(\lambda=0.71073 \AA$ \&). Scanning electron microscopy (SEM , FEI Quanta $250 \mathrm{Feg}$, Oregon, USA) was used to characterize surface morphology. Fluorescence images were recorded via fluorescence microscopy (FM, Olympus IX2-ILL100, New Jersey, USA). Photoluminescence emission spectra were recorded by Varian Cary Fluorescence Spectrophotometer (Palo Alto, USA). Atomic force microscopy (AFM) images were taken by using digital instruments-MMSPM Nanoscope IV (Tonawanda, NY, USA). A lab-made drop-tower system was designed and prepared consisting of USB2000+ Preconfigured 200-850 nm UV-vis spectrophotometer and fiber optic cable (Ocean Optics, Florida, USA). Piezoelectricity measurements were performed by using digital storage oscilloscope (GDS1000-U Series, New Taipei City, Taiwan).

Synthesis of EuD 4 TEA. For the synthesis of $\mathrm{EuD}_{4} \mathrm{TEA}, 13 \mathrm{mmol}$ of 1,3-diphenyl-1,3-propanedione (DBM) was dissolved in $50 \mathrm{~mL}$ of anhydrous ethyl alcohol at $100{ }^{\circ} \mathrm{C} .{ }^{30}$ After complete dissolution, 14 mmol of triethylamine (TEA) was added into the hot solution. Separately, $4 \mathrm{mmol}$ of europium(III) nitrate hexahydrate was dissolved in $25 \mathrm{~mL}$ of anhydrous warm ethyl alcohol, and the solution was sonicated for 2 min using an ultrasonic bath. This europium salt solution was then added to the DBM and TEA solution. The reaction was stirred and heated at $200{ }^{\circ} \mathrm{C}$ for $1 \mathrm{~h}$ under controlled conditions. During this period, the solution became clear. The solution was then kept aside to cool to room temperature. To induce the formation of excess crystal particles, the solution was then placed into the refrigerator at $+4{ }^{\circ} \mathrm{C}$. The formed crystal particles were filtered by using vacuum filtration followed by rinsing the crystals with pure ethyl alcohol and then drying in air.

Crystallography of EuD $\mathrm{D}_{4}$ TEA. Single crystal X-ray diffraction data were collected at $100 \mathrm{~K}$ using a crystal having approximate dimensions of $0.041 \times 0.063 \times 0.203 \mathrm{~mm}^{3}$. A total of 10676 reflections $(0.83 \AA$ resolution) were indexed to a primitive monoclinic unit cell of $a=$ 

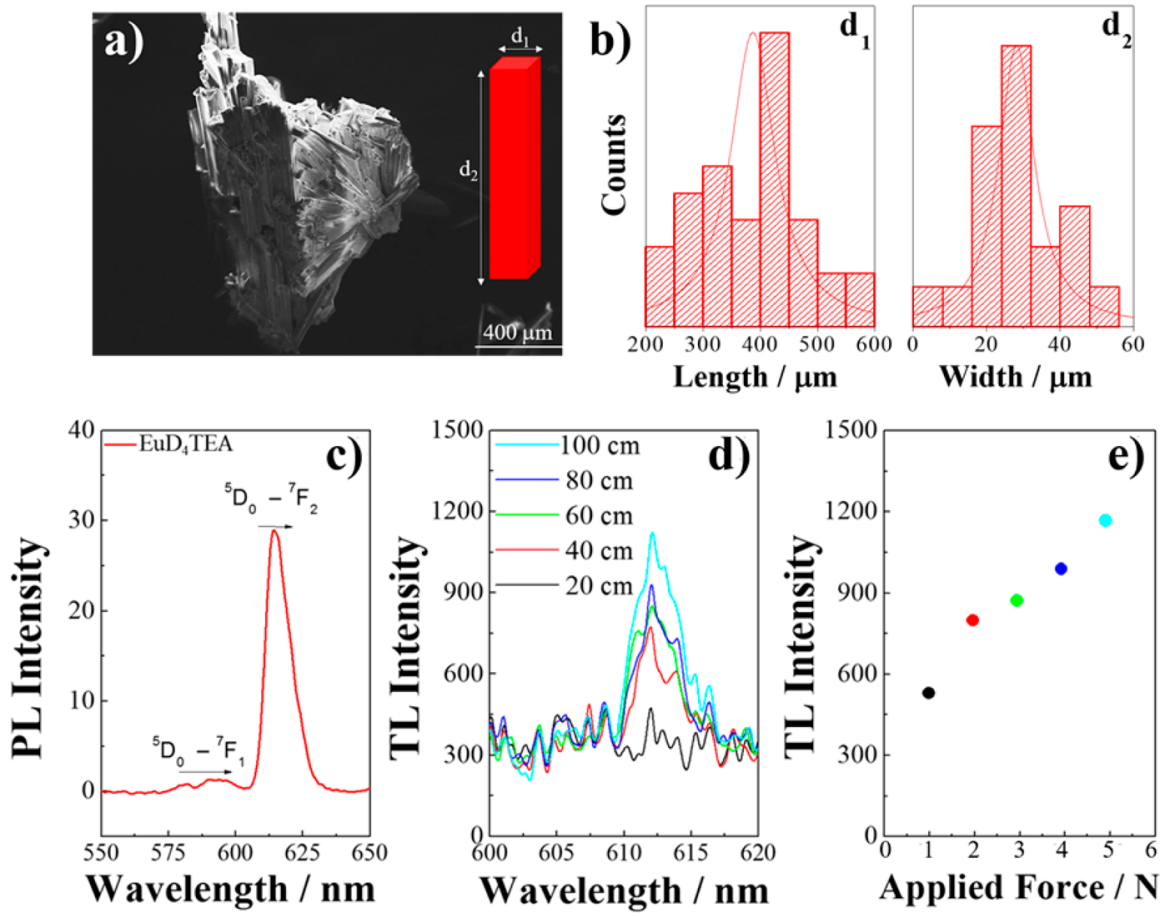

Figure 1. Characterization of $\mathrm{EuD}_{4} \mathrm{TEA}$ crystalline particles: (a) SEM image, (b) particle size distribution, (c) PL spectrum (87 $\mu \mathrm{M}$ ), (d) TL spectrum $(25 \mathrm{mg})$, and (e) TL spectrum with respect to applied force $(0.98-4.98 \mathrm{~N})$.

9.0297(7) $\AA, b=24.830(3) \AA ̊, c=25.203(2) \AA ⿻, \beta=91.323(3)^{\circ}$, volume $=5649.2(9) \AA^{3}$. The data were processed as a two-component twin, where twin contributions were distinguished using the program cell_now, and data scaling and absorption correction was performed using TWINABS. ${ }^{45,46}$ The space group $P 2_{1}$ was identified from the systematic absences. The structure was solved by direct methods, and subsequently refined by full matrix least-squares on $F^{2}$ using the SHELXTL software package. ${ }^{47}$ Hydrogen atoms were placed at geometrically calculated positions. The final structural model converged to $R_{1}=0.0640$ for the observed data.

Preparation of EuD 4 TEA/Polymer Composites. Two different processes were carried out for the preparation of $\mathrm{EuD}_{4} \mathrm{TEA} /$ polymer composites (Scheme 1). $\mathrm{EuD}_{4} \mathrm{TEA}$ crystalline particles were integrated into four different polymers: PMMA, PS, PU, and PVDF. In the blending process, the polymer solution was prepared by dissolving the polymer in $\mathrm{N}, \mathrm{N}$-dimethylformamide (DMF). After complete dissolution was achieved, crystalline particles of $\mathrm{EuD}_{4} \mathrm{TEA}(125 \mathrm{mg})$ were added into the polymer solution with a concentration of $15 \mathrm{wt} \%$. When a homogeneously mixed solution was obtained, the solution was cast on a glass substrate, and the annealing process was carried out at $100{ }^{\circ} \mathrm{C}$ for $2 \mathrm{~h}$ to obtain the blended TL crystal-polymer composites. In the surface impregnation process, the polymer films were first obtained by a film-casting and annealing process from pristine polymer solution with a concentration of $15 \mathrm{wt} \%$. Separately, $125 \mathrm{mg}$ of crystalline particles were uniformly dispersed in $10 \mathrm{~mL}$ of distilled water. The transparent polymer film was put into the aqueous dispersion of crystals and treated for 1 day by shaking the reactor to ensure that crystalline particles were adsorbed onto the surface of the polymer film. Eventually, composites of the TL crystals impregnated in the surface of the polymers were obtained. For both processes, the thickness of polymer composite was around $100 \mu \mathrm{m}$. Additionally, the percentage of crystalline particles by mass with respect to polymer solution by volume was fixed as $2.5 \mathrm{wt} \%$.

Measurement of Triboluminescence. The triboluminescence emission of $\mathrm{EuD}_{4} \mathrm{TEA}$ and $\mathrm{EuD}_{4} \mathrm{TEA} /$ polymer composites was obtained by using a drop-tower mechanism. The system was specifically designed for TL testing (Scheme S1). The material was placed into a sample holder within a black box (to exclude ambient light interference). A $50 \mathrm{~g}$ steel ball with a diameter of $1 \mathrm{~cm}$ was positioned on a pullable pin at a set distance of $40 \mathrm{in} .(100 \mathrm{~cm})$ above the material. When the pin is pulled, the ball falls and hits the material, and TL emission occurs. A fiber optic cable was preinserted directly through a small hole inside the black box to capture and transfer the impact radiation to a spectrophotometer. The TL signal was obtained by quick-view fluorescence mode as a graph of triboluminescence emission with respect to wavelength. In the principle of impact from falling object, potential energy is assumed to convert kinetic energy without having dissipation so that the $50.0 \mathrm{~cm}$ height causes $2.45 \mathrm{~N}$ mechanical impact for the measurement of TL response of composite.

Measurement of Piezoelectricity. The schematic illustration of setup for piezoelectricity measurement is given in Scheme S2. The drop-tower mechanism was combined with an oscilloscope for the measurement of resulting piezoelectric voltage. The composite film was placed on the smooth surface. Two conductive connectors were fixed to the end-points of composite film. Two ends were connected the probe of the oscilloscope. The probe is a sharp tip, and it is a point for the main circuit. For the voltage characterization, the peak-to-peak amplitude was measured as the absolute difference between a high and low voltage point of a signal. In order to create mechanical stress, the same methodology was applied as in described for the measurement of triboluminescence intensity. The metal ball $(50 \mathrm{~g})$ was positioned at $50 \mathrm{~cm}$ higher than test sample. In the measurement of piezoelectricity, the actual potential difference from the composite material itself by mechanical action is recorded. Each slot was set to $250 \mathrm{~ns}$ (ns) in the range of 0-4000 units. Each slot occupies $0.625 \mathrm{~ns}$. The interval for piezoelectric voltage was determined as $300 \mathrm{~ns}$ in the range of $1100-$ 1400 unit. From 0 to 1100 , the measurement voltage was called a piezo trigger to stabilize the system control and to be sure that the trigger point is fixed at the 0 point. The operating voltage was set for peak to peak separation from +30 to $-30 \mathrm{mV}$. When the pin is pulled and the ball hits the material, the resulting piezoelectric voltage is recorded by read-out via oscilloscope. By using the trigger system of oscilloscope, the signal is stabilized and saved. As a result, the piezoelectric signals of composite was recorded as piezoelectric voltage $(\mathrm{mV})$ with respect to time (ns). 


\section{RESULTS AND DISCUSSION}

EuD $_{4}$ TEA Crystals. The synthesized EuD $\mathrm{E}_{4} \mathrm{TEA}$ crystals were investigated by scanning electron microscopy (SEM) to examine the morphology of crystalline particles as shown in Figure 1a. The largest particles consisted of high number of assembled individual crystals each of which is rectangular in shape. The length and width distribution of the crystals in Figure $1 \mathrm{~b}$ indicates a Gaussian distribution with an average size of 400 and $30 \mu \mathrm{m}$, respectively. Photoluminescence of $\mathrm{EuD}_{4}$ TEA $(87 \mu \mathrm{M})$ was measured in DMF and the spectrum is given in Figure 1c. The spectrum indicates a classic transition for $\mathrm{Eu}$ (III)-based compounds, and the main transition from ${ }^{5} \mathrm{D}_{0}$ to ${ }^{7} \mathrm{~F}_{2}$ was centered at $614 \mathrm{~nm}$. TL spectrum of $\mathrm{EuD}_{4}$ TEA $(25$ $\mathrm{mg}$ ) was obtained by using the drop-tower system, and the spectra as a function of height are given in Figure 1d. The longer height translated to a larger compression force on the crystalline particles; therefore, the percentage of emitted light was observed to be larger from a $100 \mathrm{~cm}$ height. Additionally, the change on TL emission as a function of height was characterized with respect to applied force and shown in Figure 1e. Regardless of the impact velocity (developed from drops from different heights), the wavelength and the shape of the spectra remain unchanged. The signal with a shoulder appears at $614 \mathrm{~nm}$. Not surprisingly, increasing the impact velocity increases the intensity of the signal. While the applied force was changed from 0.98 to $4.98 \mathrm{~N}$ (calculated by free falling of the ball), the emitted TL intensity increased more than two-fold.

Although the origin of TL emission remains unclear, it is well-known that the crystal structure, particularly the lack of center of symmetry, plays a key role. The room-temperature crystal structure of $\mathrm{EuD}_{4}$ (TEA) has been previously discussed in the literature with varying conclusions. An initial study proposed a centrosymmetric crystal structure for $\mathrm{EuD}_{4}(\mathrm{TEA})$ in space group $I 2 / a$, where structural disorder was proposed as a contributor to the observed TL behavior. ${ }^{31}$ The structure was later reinvestigated, and a noncentrosymmetric model was developed in space group $I a$, having less disorder and consistent with most correlations of TL and a lack of a center of symmetry. ${ }^{46}$ The low-temperature data $(100 \mathrm{~K})$ of the present study also support a noncentrosymmetric space group, with the systematic absences suggesting a twinned crystal in space group $P 2_{1}$, having similar lattice parameters to the body-centered monoclinic structures at room temperature. Considering the systematic absence data both before and after separation of the twin components led to space group $P 2_{1}$ at $100 \mathrm{~K}$. The resulting Flack parameter obtained from the final structure refinement is likewise consistent with a noncentrosymmetric space group.

Crystallographic data (XRD data table) from the structure refinement is given in Table S1. At $100 \mathrm{~K}$, neither the ligand nor cation atoms exhibit significant disorder. The structure of the europium complex is shown in Figure 2. Europium is eightcoordinate with oxygen atoms of the 1,3-diphenyl-1,3-propanedionato ligands to form the tetrabidentate anionic $\mathrm{Eu}(\mathrm{III})$ complex. The anionic europium complex forms colorless crystals with the protonated triethylammonium molecule $\left(\mathrm{Et}_{3} \mathrm{NH}^{+}\right)$providing charge balance. The average $\mathrm{Eu}-\mathrm{O}$ bond distances in chelate ring is 2.387(17) $\AA$ (Table S2). The eightcoordinate rare-earth dibenzoylmethide (propandionato) complexes typically have dodecahedral or square-antiprismatic structures. $^{48-50}$ In the title compound, eight-coordinate europium has square-antiprismatic coordination geometry.

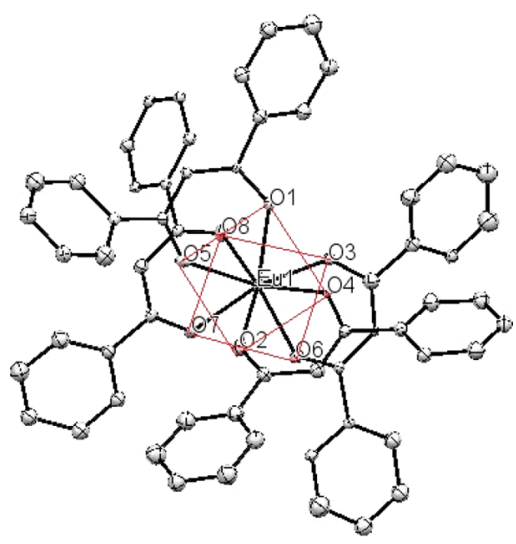

Figure 2. Molecular structure of $\mathrm{EuD}_{4}$ TEA with square antiprismatic geometry of eight coordinated europium.

Strong $\mathrm{Et}_{3} \mathrm{NH}$ - - -O hydrogen bonds (Table S3) in the structure stabilize the long-range packing.

Triboluminescence of EuD 4 TEA/Polymer Composites. The TL performance of the composites was investigated using the drop-tower system. Figure 3 presents the TL spectra of $\mathrm{EuD}_{4}$ TEA associated with four different polymers (PMMA, PS, $\mathrm{PU}$, and PVDF) employing two procedures (blending and surface impregnation). The composite films prepared by blending have no TL response (at least using the current setup) under mechanical force where the weight percentage of TL crystals in composite is at $2.5 \mathrm{wt} \%$ (Figure $3 \mathrm{a}$ ). In the dissolution process, $\mathrm{EuD}_{4} \mathrm{TEA}$ crystals have been molecularly dispersed so that the crystalline structure is destroyed. Since TL responses have been obtained from the fracture of triggering the metal-nitrogen bonds of $\mathrm{Eu}-\mathrm{N}\left(\mathrm{CH}_{2} \mathrm{CH}_{3}\right)_{3}$, a detectable $\mathrm{TL}$ response does not appear. However, the PU-based composite blended with $10-99$ wt $\% \mathrm{EuD}_{4} \mathrm{TEA}$ in the polymer solution did exhibit a TL response that correlated with the amount of $\mathrm{EuD}_{4}$ TEA (Figure $3 \mathrm{~b}$ ). Thus, when [TL] is more than $10 \mathrm{wt} \%$, the composite started to give a TL signal upon application of one drop. This seems to be a function of the solubility limit of the crystalline particles in the polymer solution. Fluorescence microscopy images of the blended composite (Figure S1) showed that the dissolution of particles in the polymer solution reached up to maximum solubility after 10 wt \%; therefore, nondissolved crystalline particles were dispersed on polymer film surface which is the main source of TL signal.

In contrast, the composites prepared by surface impregnation show remarkable TL response as a function of number of drop even at low impact velocity (Figure 3c). The development of $\mathrm{TL}$ response, in contrast to that of the composites prepared by blending, may originate from the physical form of crystalline particles in the composites. TL crystals in surface-impregnated composites are positioned on the surface of the polymer film and are preserving their solid form.

The chemistry of the polymer also plays a significant role in TL performance. The emitted TL intensity after the applied first drop depends greatly on the chemistry of the polymer. Upon the first drop, the intensities of the TL signal of the composites are 6000, 3500, 3000, and 4500 a.u. for PMMA, PS, PU, and PVDF, respectively. The loss of TL emission with respect to number of drops is also polymer-dependent (Figure 3d). The TL response of EuD ${ }_{4}$ TEA crystals in PMMA, PS, and PVDF is extinguished after 7,11 , and 9 drops, respectively. The 

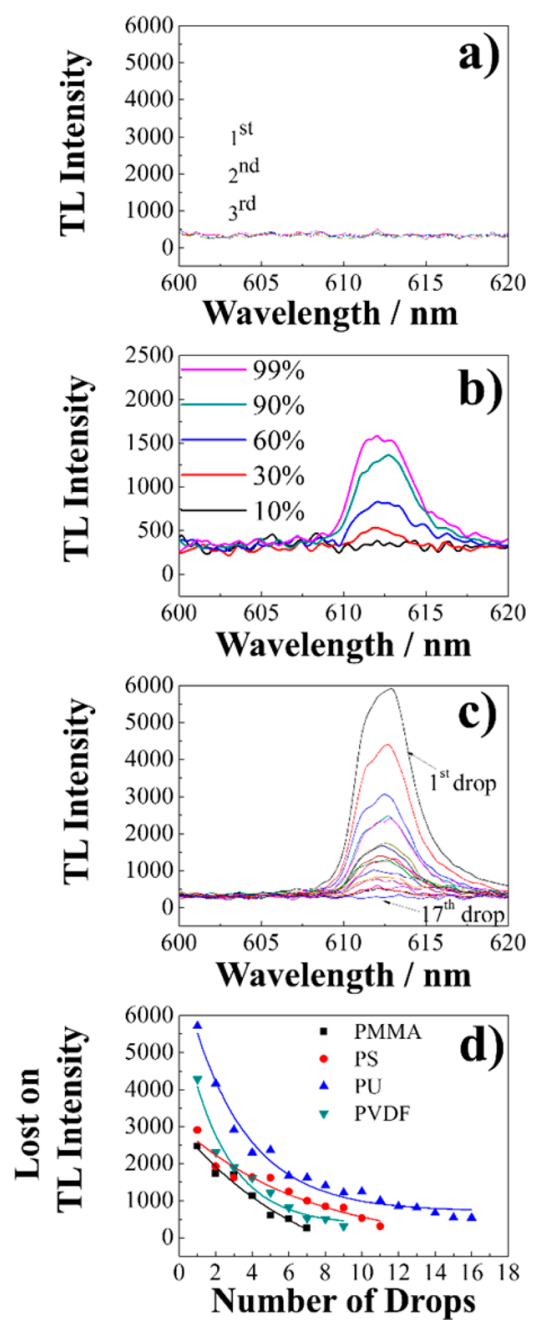

Figure 3. (a) TL spectrum of the composites prepared by blending, (b) TL response of PU-based blended composites at different TL crystal content, (c) PU-based composite prepared by surface impregnation, and (d) loss of TL emission of surface impregnated composites with associated with four different polymers (PMMA, PS, $\mathrm{PU}$, and PVDF) as a function of number of drop.

response of the same crystals, however, can withstand 17 drops for the PU-based composite. The TL intensity exhibits exponential decay with the number of drops, independent of the polymer system.

Since the number of falls breaks the crystals, the size of particles was determined to understand the effect of particle size on TL performance. The composite prepared by PU is shown as a representative response. SEM images of PU-based composites were periodically captured after each drop. Figure 4a,b show the images of initial crystals compared to those after the 17th drop, respectively. Moreover, the particle size distributions after a series of impacts were also obtained (Figure 4c). All distributions show Gaussian behavior, and mean diameters are follows: 400, 150, 100, 80, and $50 \mu \mathrm{m}$ for before drop and after $1,7,11$, and 17 drops, respectively. When the number of drops increases, the size of particles becomes inevitably smaller.

Along with the size of particles, the interaction of TL crystals with the neat polymer film surface also plays an important role in TL performance. The composites prepared by surface impregnation yield better TL performance. In this approach the
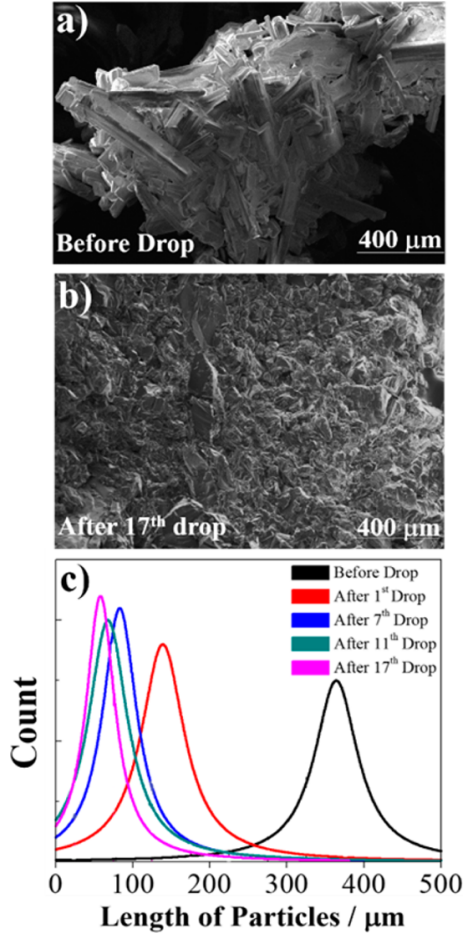

Figure 4. SEM images of PU-based surface impregnated composite (a) before drop and (b) after 17 th drop and (c) particle size distribution collected after each drop.

crystalline particles are located closer to the surface. The surface features of the cast polymer films were investigated by tapping mode AFM images (Figure 5). The difference of TL response for the polymer employed for testing may be due to the variation of surface roughness. The surface of neat PMMA film (Figure 5a) is smooth, and its surface roughness is $0.3 \mathrm{~nm}$. The surface of PS (Figure $5 b$ ) is rough compared to the one of PMMA, having $2.2 \mathrm{~nm}$ surface roughness. However, PU (Figure 5c) and PVDF (Figure 5d) show still higher surface roughnesses of 15.6 and $18.8 \mathrm{~nm}$, respectively. It is worth pointing out that the surface of PU and PVDF polymer films have rougher surface than the other polymer films. The difference in roughness may be originated from the formation of breath figure for PU and PVDF where small droplets coagulate on the surface by the condensation of solvent. ${ }^{51}$

The surface roughness appears to affect the capacity to load $\mathrm{EuD}_{4}$ TEA crystalline particles on the film surface. The weight percent of $\mathrm{EuD}_{4}$ TEA particles was derived using the difference between the total amount of dispersed crystalline particles in water and the remaining amount of dispersed crystals after treatment. Each measurement was performed three times. The average amounts of $\mathrm{EuD}_{4}$ TEA held on the polymer surfaces are $87,85,55$, and $30 \%$ for PVDF, PU, PS, and PMMA, respectively (Figure 6). From the obtained percentage values, the mass ratio of $\mathrm{EuD}_{4} \mathrm{TEA}$ in the polymer solution was calculated $0.75,1.37,2.10$, and $2.15 \%$ for PMMA, PS, PU, and PVDF, respectively. A similar relationship exists between surface roughness and the amount of TL particles held by the film surface, where rougher polymer surfaces are receptive to a higher amount of TL crystals.

In the case of 85 wt \% loaded for $\mathrm{Eu}(\mathrm{III})$-based composite, $\mathrm{TL}$ at the first drop of PU-based surface impregnated composite has the highest intensity, even though the impregnated crystalline particles are less concentrated than 
a) PMMA

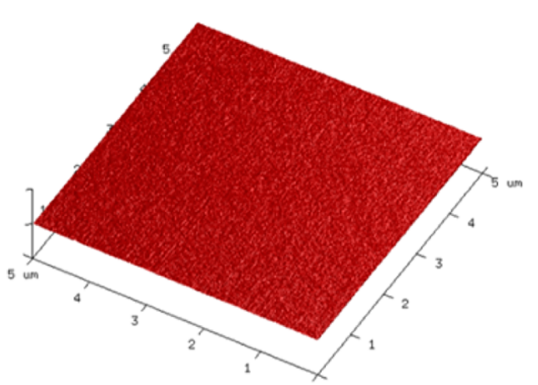

c) $\mathbf{P U}$

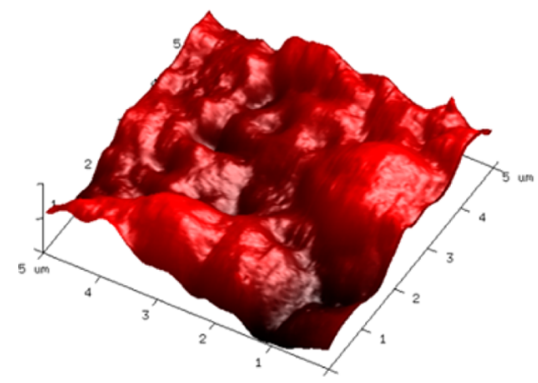

b) PS

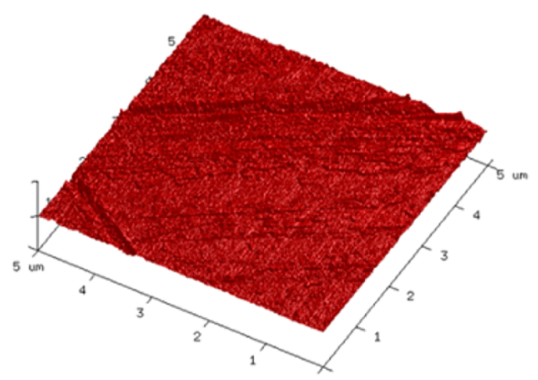

d) PVDF

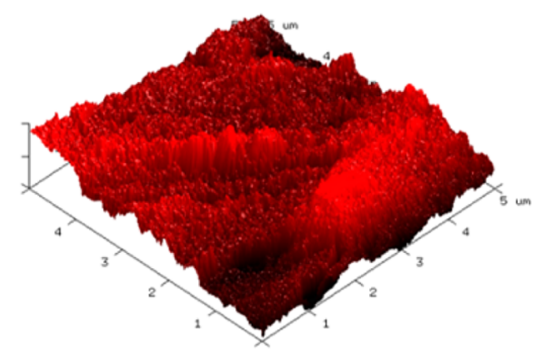

Figure 5. AFM images of surface of polymer films prepared by casting:

(a) PMMA, (b) PS, (c) PU, and (d) PVDF.

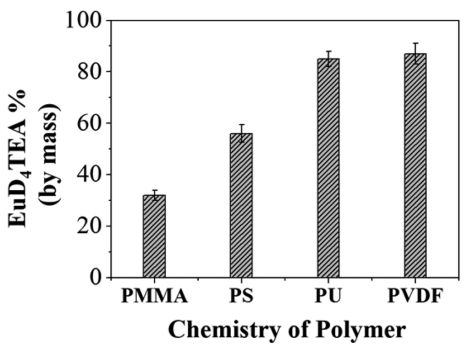

Figure 6. Weight amount of loaded crystalline particles on surface impregnated composite films with respect to chemistry of polymer.

those on the PVDF film surface. The origin of this result could be the opaque nature of PVDF film. Strong scattering occurs during the propagation of TL response upon mechanical impact. In contrast, it could be readily propagated in transparent media for the transparent PU film (Figure S2). Another reason for exhibiting longer TL response is that the nitrogen and ether-oxygen groups of PU may have a chemical interaction with the amine and benzoyl groups of $\mathrm{EuD}_{4} \mathrm{TEA}$ crystals.

The TL crystals integrated into polymers were further examined under the FM upon excitation with UV light $(\lambda=365$ $\mathrm{nm})$. Figure 7 exhibits the fluorescence microscopy images of composite films with TL crystals loaded. Note that these polymers show no intrinsic emission. In the composites prepared by surface impregnation, the signals of red emission from $\mathrm{Eu}(\mathrm{III})$-based composites were observed, indicating that the crystalline particles were fairly uniformly distributed in the host PU and PVDF polymer matrices. The crystalline particles were dispersed on the surface of the polymeric films. The amount of dispersed particles increases in the order of PMMA $<$ PS < PU < PVDF described above is supported by the FM measurements. PVDF and PU polymer surfaces show the highest area of TL crystals due to the high surface roughness of

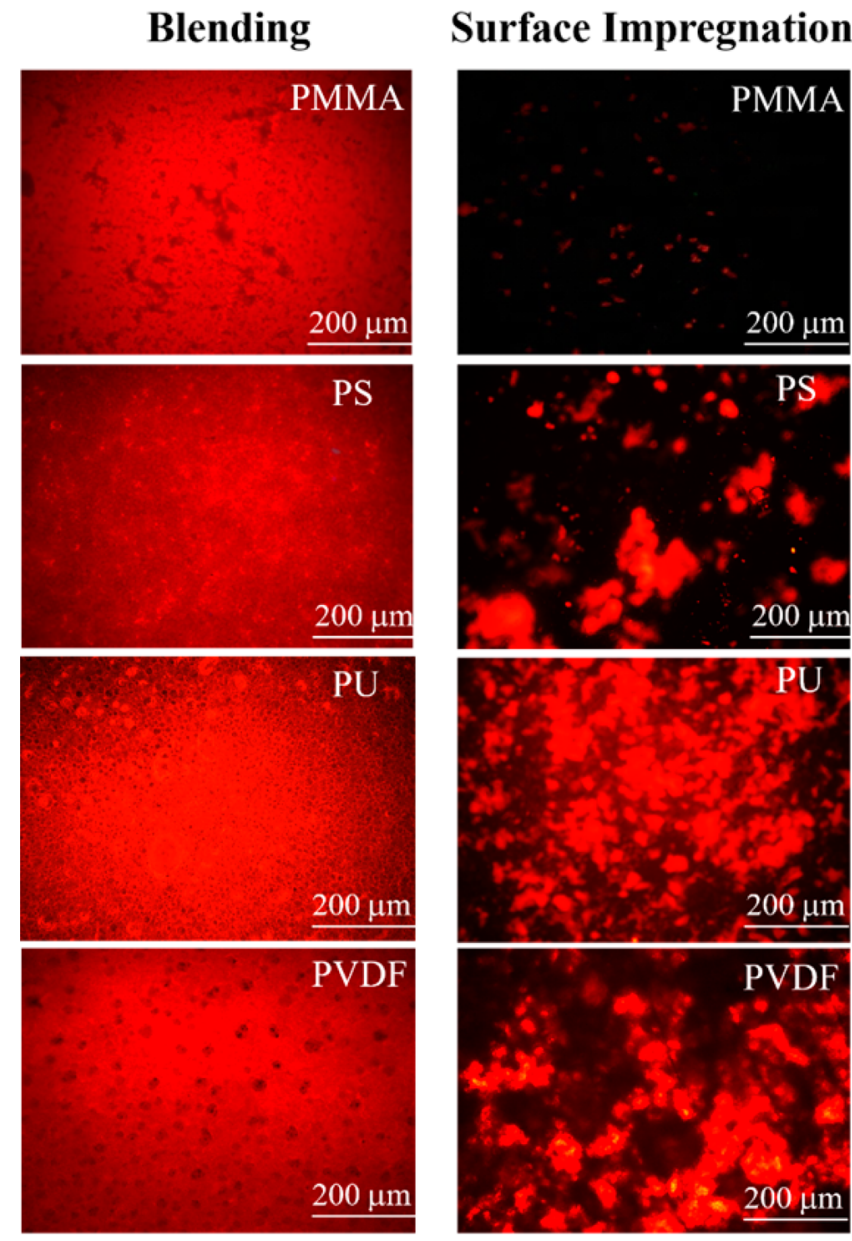

Figure 7. FM images of composites with respect to both type of process and chemistry of polymer. 
both polymers and chemical affinity of PU. For PMMA composite, only very small red regions from the TL crystal domains are evident. These domains are homogeneously dispersed over polymer film surface. In contrast, the area occupied by TL crystalline domains increases significantly in both PU and PVDF composites.

According to the X-ray data, the $\mathrm{EuD}_{4} \mathrm{TEA}$ compound adopts a noncentrosymmetric structure that permits piezoelectric behavior. The highest voltage separation was recorded as the maximum produced piezoelectric voltage. When the mechanical stress is carried out, the trigger is pulled around 30 ns shown in Figure 8 for measurement interval and starts to

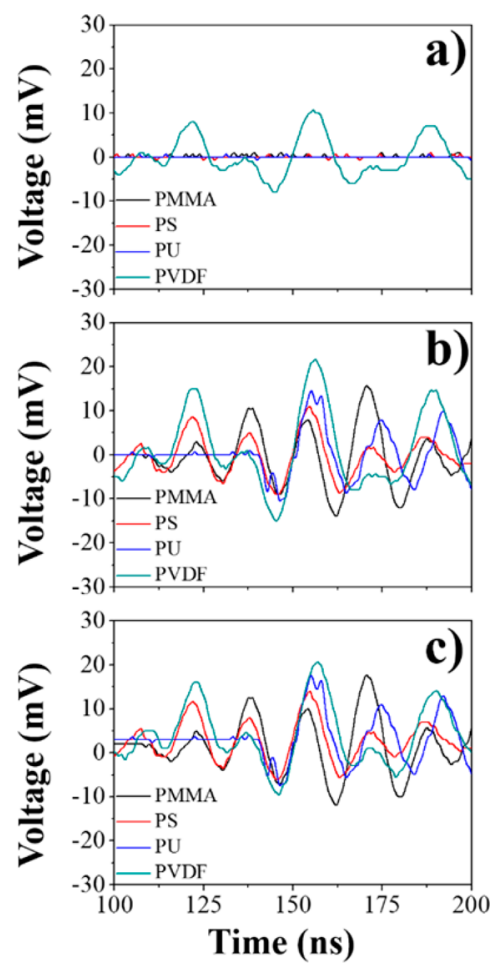

Figure 8. Piezoelectric response of (a) neat polymer films, (b) blended composites, and (c) surface impregnated composites.

accelerate. For each case, the highest peak-to-peak separation providing by distributed electrical charges appears between 150 and $165 \mathrm{~ns}$. After the time of $165 \mathrm{~ns}$, the effect of mechanical stress on piezoelectric materials was performed, and the produced electrical charges started to be balanced. Therefore, the oscillation has left and ended. Table S4 shows the minimum, maximum, and total voltage change of neat polymer film and composites. Among the neat polymer films, only PVDF exhibits piezoelectricity after the application of mechanical force. PMMA, PS, and PU polymer films show no response. In the composite films, the piezoelectric behavior of crystalline particles leads to an observed voltage change for each composite upon application of force. There is a trend for two processes that the percentage of produced voltage increases from PMMA to PVDF.

\section{CONCLUSION}

Micrometer-sized europium tetrakis(dibenzoylmethide) triethylammonium $\left(\mathrm{EuD}_{4} \mathrm{TEA}\right)$ crystals with rectangular prism shape were synthesized in hot alcohol solutions. The crystal structure was confirmed to be noncentrosymmetric by single crystal X-ray diffraction. EuD 4 TEA/polymer composites were successfully prepared by blending and surface impregnation approaches. The surface impregnation process appears to be both a practical and economical approach to induce an optical response, particularly at low concentrations. The TL intensity of the composites shows exponential decay with the number of free falls, independent of the chemistry of the polymers. The PU-based surface-impregnated composite shows the highest TL intensity and longest TL performance as a function of the number of drops due to its better transparency, higher surface roughness, and chemical interactions with $\mathrm{EuD}_{4} \mathrm{TEA}$. The percentage mass amount of $\mathrm{EuD}_{4} \mathrm{TEA}$ was measured as $2.1 \mathrm{wt}$ $\%$ in polymer solution. The TL response from the composite was measured in the range of $2.45-42.0 \mathrm{~N}$ quantitatively from drop-tower system (fixed height: $50 \mathrm{~cm}$ and weight of drop: 50 g). The TL emission of PU-based surface-impregnated composite expired after 17 drops, and the TL yield changes with impact energy were determined to be in the range of $0.25-4.2 \mathrm{~J}$. This study verifies the feasibility of $\mathrm{EuD}_{4} \mathrm{TEA} /$ polymer composites in impact sensor applications. $\mathrm{EuD}_{4} \mathrm{TEA} /$ PU composite prepared by surface impregnation is examined as a potential new piezoelectric material as well.

\section{ASSOCIATED CONTENT}

Supporting Information

The Supporting Information is available free of charge on the ACS Publications website at DOI: 10.1021/acsami.6b16330.

Drop-tower mechanism schematic, piezoelectric measurement setup, FM images, photos of polymer films, Xray crystal data, bond lengths and angles, minimum, maximum, and total voltage values of polymer films (PDF)

\section{AUTHOR INFORMATION}

\section{Corresponding Author}

*E-mail: mdemir@iyte.edu.tr. Tel.: +90 232750 7511. Fax: +90 2327507509.

ORCID

Colin D. McMillen: 0000-0002-7773-8797

Mustafa M. Demir: 0000-0003-1309-3990

Funding

The Scientific and Technological Research Council of Turkey (TUBITAK) for the research encoded with KBAG-114Z292.

\section{Notes}

The authors declare no competing financial interest.

\section{ACKNOWLEDGMENTS}

We thank the Center for Materials Research of Izmir Institute of Technology for microscopy work and Prof. Sarıçiftçi for helpful discussion at MACRO 2016.

\section{REFERENCES}

(1) Bakis, C. E.; Bank, L. C.; Brown, V. L.; Cosenza, E.; Davalos, J. F.; Lesko, J. J.; Machida, A.; Rizkalla, S. H.; Triantafillou, T. C. Fiberreinforced Polymer Composites for Construction-state-of-the-art Review. J. Compos. Constr. 2002, 6 (2), 73-87.

(2) Balazs, A. C.; Emrick, T.; Russell, T. P. Nanoparticle Polymer Composites: Where Two Small Worlds Meet. Science 2006, 314 (5802), 1107-1110.

(3) Chandra, B. P.; Xu, C. N.; Yamada, H.; Zheng, X. G. Luminescence Induced by Elastic Deformation of ZnS:Mn Nanoparticles. J. Lumin. 2010, 130 (3), 442-450. 
(4) Agyeman, O.; Xu, C. N.; Suzuki, M.; Zheng, X. G. Upgrading the Triboluminescence of ZnS: Mn Film by Optimization of Sputtering and Thermal Annealing Conditions. J. Mater. Res. 2002, 17 (5), 959963.

(5) Aich, N.; Appalla, A.; Saleh, N. B.; Ziehl, P. Triboluminescence for Distributed Damage Assessment in Cement-based Materials. J. Intell. Mater. Syst. Struct. 2013, 24 (14), 1714-1721.

(6) Hadzic, R.; John, S.; Herszberg, I. Structural Integrity Analysis of Embedded Optical Fibres in Composite Structures. Compos. Struct. 1999, 47 (1-4), 759-765.

(7) Hardy, G. E.; Zink, J. I. Triboluminescence and Pressuredependence of Photoluminescence of Tetrahedral Manganese(II) Complexes. Inorg. Chem. 1976, 15 (12), 3061-3065.

(8) Hosur, M. V.; Murthy, C. R. L.; Ramamurthy, T. S.; Shet, A. Estimation of Impact-induced Damage in CFRP Laminates Through Ultrasonic Imaging. NDT\&amp;E Int. 1998, 31 (5), 359-374.

(9) Mancini, S.; Tumino, G.; Gaudenzi, P. Structural Health Monitoring for Future Space Vehicles. J. Intell. Mater. Syst. Struct. 2006, 17 (7), 577-585.

(10) Jeong, S. M.; Song, S.; Joo, K. I.; Kim, J.; Hwang, S. H.; Jeong, J.; Kim, H. Bright, Wind-driven White Mechanoluminescence from Zinc Sulphide Microparticles Embedded in a Polydimethylsiloxane Elastomer. Energy Environ. Sci. 2014, 7 (10), 3338-3346.

(11) Jin, X.; Gotz, M.; Wille, S.; Mishra, Y. K.; Adelung, R.; Zollfrank, C. A Novel Concept for Self-Reporting Materials: Stress Sensitive Photoluminescence in $\mathrm{ZnO}$ Tetrapod Filled Elastomers. Adv. Mater. 2013, 25 (9), 1342-1347.

(12) Leelachao, S.; Muraishi, S.; Sannomiya, T.; Shi, J.; Nakamura, Y. Correlation of Triboluminescence and Contact Stresses in ZnS: Mn/ polymeric Matrix Composite. J. Lumin. 2016, 170, 24-29.

(13) Olawale, D. O.; Dickens, T.; Sullivan, W. G.; Okoli, O. I.; Sobanjo, J. O.; Wang, B. Progress in Triboluminescence-based Smart Optical Sensor System. J. Lumin. 2011, 131 (7), 1407-1418.

(14) Chandra, B. P.; Sonwane, V. D.; Haldar, B. K.; Pandey, S. Mechanoluminescence Glow Curves of Rare-earth Doped Strontium Aluminate Phosphors. Opt. Mater. 2011, 33 (3), 444-451.

(15) Xu, C. N.; Yamada, H.; Wang, X. S.; Zheng, X. G. Strong Elasticoluminescence from Monoclinic-structure $\mathrm{SrAl}_{2} \mathrm{O}_{4}$. Appl. Phys. Lett. 2004, 84 (16), 3040-3042.

(16) Sohn, K. S.; Seo, S. Y.; Kwon, Y. N.; Park, H. D. Direct Observation of Crack Tip Stress Field Using the Mechanoluminescence of $\mathrm{SrAl}_{2} \mathrm{O}_{4}:(\mathrm{Eu}, \mathrm{Dy}, \mathrm{Nd})$. J. Am. Ceram. Soc. 2002, 85 (3), 712714.

(17) Ishihara, T.; Tanaka, K.; Fujita, K.; Hirao, K.; Soga, N. Full Color Triboluminescence of Rare-earth-doped Hexacelsian ( $\left.\mathrm{BaAl}_{2} \mathrm{Si}_{2} \mathrm{O}_{8}\right)$. Solid State Commun. 1998, 107 (12), 763-767.

(18) Fontenot, R. S.; Owens, C. A.; Bhat, K. N.; Hollerman, W. A.; Aggarwal, M. D. Magnesium Tetrakis Dibenzoylmethide Triethylammonium: A Novel Blue Emitting Phosphor. Mater. Lett. 2015, 146, 911.

(19) Marchetti, F.; Di Nicola, C.; Pettinari, R.; Timokhin, I.; Pettinari, C. Synthesis of a Photoluminescent and Triboluminescent Copper(I) Compound: An Experiment for an Advanced Inorganic Chemistry Laboratory. J. Chem. Educ. 2012, 89 (5), 652-655.

(20) Ronfard-Haret, J. C.; Valat, P.; Wintgens, V.; Kossanyi, J. Triboluminescence of Trivalent Rare Earth Ions Inserted in Polycrystalline Zinc Oxide. J. Lumin. 2000, 91 (1-2), 71-77.

(21) Eliseeva, S. V.; Pleshkov, D. N.; Lyssenko, K. A.; Lepnev, L. S.; Bunzli, J. C. G.; Kuzmina, N. P. Highly Luminescent and Triboluminescent Coordination Polymers Assembled from Lanthanide beta-Diketonates and Aromatic Bidentate O-Donor Ligands. Inorg. Chem. 2010, 49 (20), 9300-9311.

(22) Wu, W.; Narisawa, T.; Hayashi, S. Triboluminescence of 3,6dibromocarbazole. Jpn. J. Appl. Phys., Part 1 2001, 40 (3A), 12941296.

(23) Nowak, R.; Krajewska, A.; Samoc, M. Efficient Triboluminescence in N-Isopropylcarbazole. Chem. Phys. Lett. 1983, 94 (3), 270271.
(24) Sweeting, L. M.; Rheingold, A. L.; Gingerich, J. M.; Rutter, A. W.; Spence, R. A.; Cox, C. D.; Kim, T. J. Crystal Structure and Triboluminescence 0.2. 9-anthracenecarboxylic Acid and Its Esters. Chem. Mater. 1997, 9 (5), 1103-1115.

(25) Nakayama, H.; Nishida, J.; Takada, N.; Sato, H.; Yamashita, Y. Crystal Structures and Triboluminescence Based on Trifluoromethyl and Pentafluorosulfanyl Substituted Asymmetric N-Phenyl Imide Compounds. Chem. Mater. 2012, 24 (4), 671-676.

(26) Diep, V. M.; Armani, A. M. Flexible Light-Emitting Nanocomposite Based on ZnO Nanotetrapods. Nano Lett. 2016, 16, 73897393.

(27) Raja, S. N.; Olson, A. C. K.; Thorkelsson, K.; Luong, A. J.; Hsueh, L.; Chang, G.; Gludovatz, B.; Lin, L.; Xu, T.; Ritchie, R. O.; Alivisatos, A. P. Tetrapod Nanocrystals as Fluorescent Stress Probes of Electrospun Nanocomposites. Nano Lett. 2013, 13, 3915-3922.

(28) Jin, X.; Deng, M.; Kaps, S.; Zhu, X.; Hölken, I.; Mess, K.; Adelung, R.; Mishra, Y. K. Study of Tetrapodal ZnO-PDMS Composites: A Comparison of Fillers Shapes in Stiffness and Hydrophobicity Improvements. PLoS One 2014, 9 (9), e106991.

(29) Hurt, C. R.; McAvoy, N.; Bjorklund, S.; Filipescu, N. High Intensity Triboluminescence in Europium Tetrakis (Dibenzoylmethide)-triethylammonium. Nature 1966, 212 (5058), 179-180.

(30) Fontenot, R. S.; Hollerman, W. A.; Bhat, K. N.; Aggarwal, M. D. Synthesis and Characterization of Highly Triboluminescent Doped Europium Tetrakis Compounds. J. Lumin. 2012, 132 (7), 1812-1818.

(31) Sweeting, L. M.; Rheingold, A. L. Crystal Disorder and Triboluminescence - Triethylammonium Tetrakis(dibenzoylmethanato)europate. J. Am. Chem. Soc. 1987, 109 (9), 2652-2658.

(32) Fontenot, R. S.; Bhat, K. N.; Hollerman, W. A.; Aggarwal, M. D.; Nguyen, K. M. Comparison of the Triboluminescent Yield and Decay Time for Europium Dibenzoylmethide Triethylammonium Synthesized Using Different Solvents. CrystEngComm 2012, 14 (4), 13821386.

(33) Fontenot, R. S.; Hollerman, W. A.; Bhat, K. N.; Allison, S. W.; Aggarwal, M. D. Luminescent Properties of Lanthanide Dibenzoylmethide Triethylammonium Compounds. J. Theor. Appl. Phys. 2013, 7 (1), 30.

(34) Hollerman, W. A.; Fontenot, R. S.; Bhat, K. N.; Aggarwal, M. D.; Guidry, C. J.; Nguyen, K. M. Comparison of Triboluminescent Emission Yields for 27 Luminescent Materials. Opt. Mater. 2012, 34 (9), 1517-1521.

(35) Fontenot, R. S.; Hollerman, W. A.; Bhat, K. N.; Aggarwal, M. D. Effects of Added Uranium on the Triboluminescent Properties of Europium Dibenzoylmethide Triethylammonium. J. Lumin. 2013, 134, $477-482$.

(36) Fontenot, R. S.; Bhat, K. N.; Hollerman, W. A.; Aggarwal, M. D. Europium Tetrakis Dibenzoylmethide Triethylammonium: Synthesis, Additives, and Applications. In Triboluminescence: Theory, Synthesis, and Application; Olawale, O. D., Okoli, I. O. O., Fontenot, S. R., Hollerman, A. W., Eds.; Springer International Publishing: Cham, 2016; pp 147-235.

(37) Wang, F. J.; Hashimoto, K.; Tajima, K. Optical Anisotropy and Strong H-Aggregation of Poly(3-Alkylthiophene) in a Surface Monolayer. Adv. Mater. 2015, 27 (39), 6014-6020.

(38) Demir, M. M.; Ozen, B.; Ozcelik, S. Formation of Pseudoisocyanine J-Aggregates in Poly(vinyl alcohol) Fibers by Electrospinning. J. Phys. Chem. B 2009, 113, 11568-11573.

(39) Demir, M. M.; Wegner, G. Challenges in the Preparation of Optical Polymer Composites with Nanosized Pigment Particles: A Review on Recent Efforts. Macromol. Mater. Eng. 2012, 297, 838-863.

(40) Fontenot, R. S.; Allison, S. W.; Lynch, K. J.; Hollerman, W. A.; Sabri, F. Mechanical, Spectral, and Luminescence Properties of ZnS:Mn Doped PDMS. J. Lumin. 2016, 170, 194-199.

(41) Dickens, T. J.; Breaux, J.; Olawale, D. O.; Sullivan, W. G.; Okoli, O. I. Effects of ZnS:Mn Concentrated Vinyl Ester Matrices Under Flexural Loading on the Triboluminescent Yield. J. Lumin. 2012, 132 (7), 1714-1719. 
(42) Fontenot, R. S.; Hollerman, W. A.; Bhat, K. N.; Aggarwal, M. D.; Penn, B. G. Incorporating Strongly Triboluminescent Europium Dibenzoylmethide Triethylammonium into Simple Polymers. Polym. J. 2014, 46 (2), 111-116.

(43) Meuer, S.; Zentel, R. Functional Diblock Copolymers for the Integration of Triboluminescent Materials into Polymer Matrices. Macromol. Chem. Phys. 2008, 209 (2), 158-167.

(44) İncel, A.; Reddy, S. M.; Demir, M. M. A New Method to Extend the Stress Response of Triboluminescent Crystals by Using Hydrogels. Mater. Lett. 2017, 186, 210-213.

(45) Sheldrick, G. M. CELL_NOW, version 2008/4; Georg-AugustUniversitat Göttingen: Göttingen, Germany, 2008.

(46) Sheldrick, G. M. TWINABS, version 2012/1; Georg-AugustUniversitat Göttingen, Göttingen, Germany, 2012.

(47) Sheldrick, G. M. A Short History of SHELX. Acta Crystallogr., Sect. A: Found. Crystallogr. 2008, 64, 112-122.

(48) Cotton, F. A.; Daniels, L. M.; Huang, P. L. Refutation of an Alleged Example of a Disordered but Centrosymmetric Triboluminescent Crystal. Inorg. Chem. Commun. 2001, 4 (6), 319-321.

(49) Burns, J. H.; Danford, M. D. Crystal Structure of Cesium Tetrakis (hexaflouroacetylacetonato)europate and -americate. Isomorphism with the Yttrate. Inorg. Chem. 1969, 8 (8), 1780-1784.

(50) Il'inskii, A. L.; Porai-Koshits, M. A.; Aslanov, L. A.; Lazarev, P. I. Crystal and Molecular Structures of the Normal (piperidinium) Salt and Acid (diethylamine adduct) Salt of Tetrakis(benzoylacetonato)europate. J. Struct. Chem. 1972, 13 (2), 254-262.

(51) Hoa, M. L. K.; Lu, M.; Zhang, Y. Preparation of Porous Materials with Ordered Hole Structure. Adv. Colloid Interface Sci. 2006, $121(1-3), 9-23$. 